Acta Crystallographica Section B

Structural

Science

ISSN 0108-7681

Edwin A. Collier, ${ }^{\mathrm{a}} \neq$ Roger J. Davey, ${ }^{a *}$ Simon N. Black ${ }^{b}$ and Ron J. Roberts ${ }^{\mathrm{c}}$

aMolecular Materials Centre, School of Chemical Engineering and Analytical Science, The University of Manchester, PO Box 88, Sackville Street, Manchester M60 1QD, England, ${ }^{\mathbf{b}}$ Process Engineering Group, PR\&D, AstraZeneca, Silk Road Business Park, Charter Way, Macclesfield, Cheshire SK10 2NA, England, and ${ }^{C}$ Preformulation and Biopharmaceutics, PAR\&D, AstraZeneca, Silk Road Business Park, Charter Way, Macclesfield, Cheshire SK10 2NA, England

\# Current address: TransForm Pharmaceuticals Inc., 29 Hartwell Avenue, Lexington, MA 02139, USA.

Correspondence e-mail: roger.davey@manchester.ac.uk
(C) 2006 International Union of Crystallography Printed in Great Britain - all rights reserved

\title{
17 salts of ephedrine: crystal structures and packing analysis
}

The structures of two neutral and 17 salt forms of the base $(1 R$, $2 S)$-(-)-ephedrine are reported. These structures are discussed in the light of the conformers of the ephedrine moiety, the existence of bilayers and the structure determining role of the counterions. Overall, most of the salt structures are essentially derived from the observed packing of the neutral base and are dominated by the amphiphilic nature of the ephedrine molecular structure. In a few cases the size and hydrophobicity of the counterion disrupts this behaviour.

\section{Introduction}

The importance of molecular salts as solid forms in pharmaceutical formulations is well known (Stahl \& Wermuth, 2002). For a given active ingredient, the isolation and selection of a salt with the appropriate physicochemical properties involves significant screening activity and has been discussed at some length in the literature (Tong \& Whitesell, 1998; Shanker, 1994). It is apparent that over $40 \%$ of marketed salts are hydrochlorides (Gould, 1986) and this trend is reflected in the available salt structures in the Cambridge Structural Database (Allen, 2002): the November 2003 release (Collier, 2004; Jones et al., 2005) showed that of 950 salts in which one component is recorded as being active, an agent or a drug, hydrochlorides are the most common occurring as $55 \%$ of the entries, with acetates the next most popular at $17 \%$. It is also evident from the CSD records that there have been very few studies in which crystal structures of multiple salt forms of a single active drug have been reported. Recently (Lewis et al., 2005) the structures of six salts of remacemide have been determined, and the competition between hydrophilic and hydrophobic interactions as drivers for the crystal packings discussed. Our current work seeks to go further using the pharmaceutically active base $(1 R, 2 S)$-(-)-ephedrine (I) as a cation from which salts have been prepared from 17 anions, including carboxylates, sulfonates, phosphonates and inorganic species. The CSD already contains determinations for the hemihydrate (Krebs et al., 2001), mono- and dihydrogenphosphates (Hearn et al., 1973; Hearn \& Bugg, 1972) and the hydrochloride (Bergin, 1971). The entry for the anhydrous free base (Malone \& Parvez, 1978) is incomplete, containing no atomic coordinates: this structure is reported here for the first time. The available hemihydrate structure was solved from powder data at $6 \mathrm{~K}$ and so we also report here the results of our singlecrystal determination. We have, in addition, redetermined both the hydrochloride and the dihydrogen phosphate since these determinations date from the 1970s. In earlier studies (Leusen et al., 1991, 1992) the structures of five pairs of diastereomeric salts of ephedrine with a cyclic phosphoric acid
Received 17 October 2005 Accepted 3 April 2006 
Table 1

Summary of crystallographic data.

$R_{1}=R\left[F^{2}>2 \sigma\left(F^{2}\right)\right], w R_{2}=w R\left(F^{2}\right), N V=$ No. of parameters.

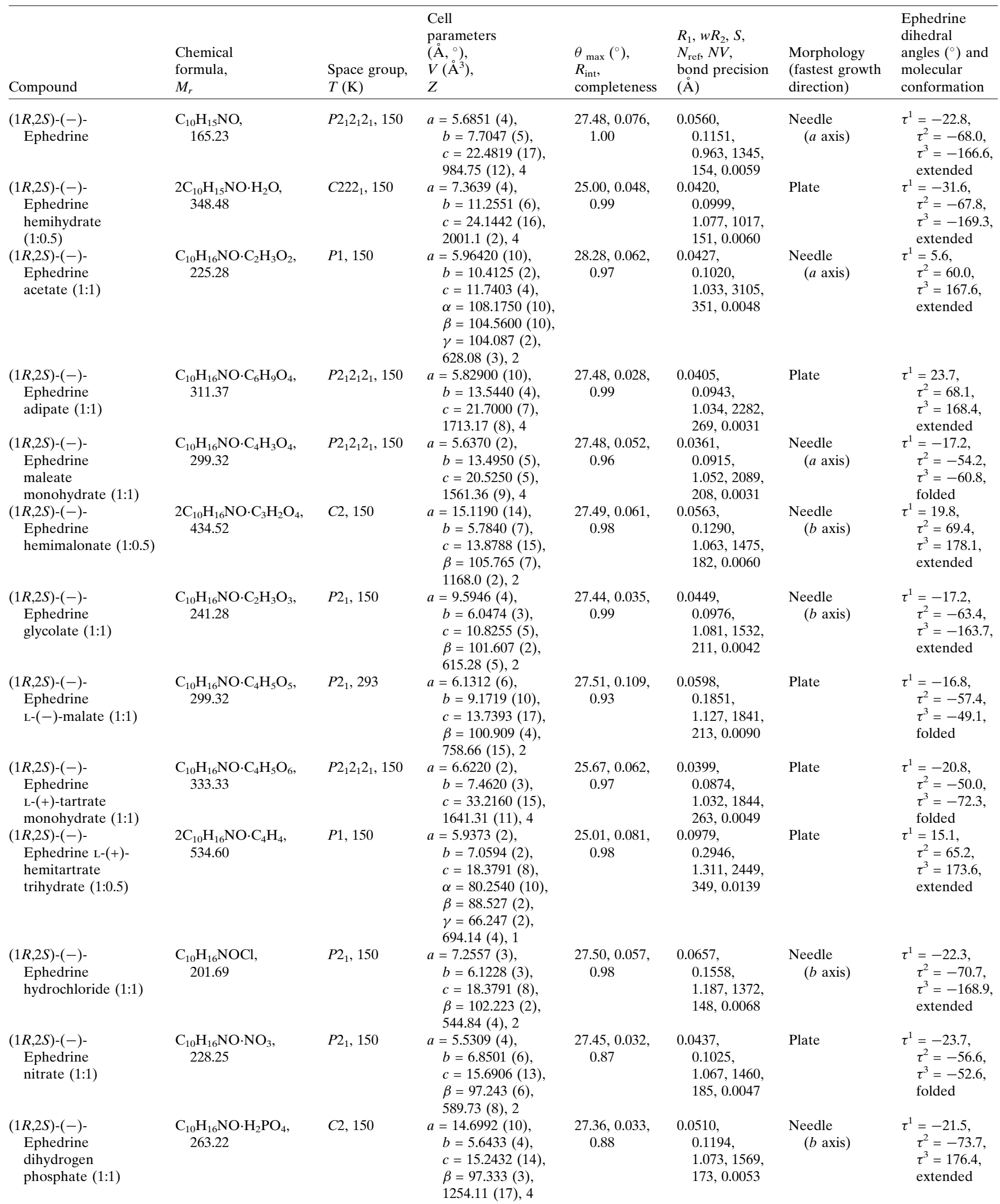


Table 1 (continued)

\begin{tabular}{|c|c|c|c|c|c|c|c|}
\hline Compound & $\begin{array}{l}\text { Chemical } \\
\text { formula, } \\
M_{r}\end{array}$ & $\begin{array}{l}\text { Space group, } \\
T(\mathrm{~K})\end{array}$ & $\begin{array}{l}\text { Cell } \\
\text { parameters } \\
\left(\AA,{ }^{\circ}\right), \\
V\left(\AA^{3}\right), \\
Z\end{array}$ & $\begin{array}{l}\theta_{\max }\left({ }^{\circ}\right), \\
R_{\text {int }}, \\
\text { completeness }\end{array}$ & $\begin{array}{l}R_{1}, w R_{2}, S, \\
N_{\text {ref }}, N V, \\
\text { bond precision } \\
(\AA)\end{array}$ & $\begin{array}{l}\text { Morphology } \\
\text { (fastest growth } \\
\text { direction) }\end{array}$ & $\begin{array}{l}\text { Ephedrine } \\
\text { dihedral } \\
\text { angles }\left({ }^{\circ}\right) \text { and } \\
\text { molecular } \\
\text { conformation }\end{array}$ \\
\hline $\begin{array}{l}(1 R, 2 S)-(-)- \\
\text { Ephedrine } \\
\text { bisulfate }(1: 1)\end{array}$ & $\begin{array}{l}\mathrm{C}_{10} \mathrm{H}_{16} \mathrm{NO} \cdot \mathrm{HSO}_{4}, \\
\quad 263.32\end{array}$ & $C 2,150$ & $\begin{array}{c}a=30.9967(17) \\
b=6.9861(4) \\
c=5.6170(3) \\
\beta=93.354(3) \\
1214.26(12), 4\end{array}$ & $\begin{array}{l}28.93,0.058 \\
\quad 0.99\end{array}$ & $\begin{array}{l}0.0735, \\
\quad 0.1253, \\
1.116,1739 \\
173,0.0057\end{array}$ & $\begin{array}{l}\text { Needle } \\
\qquad(c \text { axis })\end{array}$ & $\begin{array}{l}\tau^{1}=-25.8 \\
\tau^{2}=-50.2 \\
\tau^{3}=-60.2 \\
\text { folded }\end{array}$ \\
\hline $\begin{array}{l}(1 R, 2 S)-(-)- \\
\text { Ephedrine } \\
\text { besylate }(1: 1)\end{array}$ & $\begin{array}{l}\mathrm{C}_{10} \mathrm{H}_{16} \mathrm{NO} \cdot \mathrm{C}_{6} \mathrm{H}_{5} \mathrm{O}_{3} \mathrm{~S} \\
\quad 323.41\end{array}$ & $P 2_{1}, 150$ & $\begin{array}{c}a=5.7214(3) \\
b=20.8336(11) \\
c=6.9188(5) \\
\beta=98.409(2) \\
815.84(8), 2\end{array}$ & $\begin{array}{l}27.47,0.038 \\
\quad 0.91\end{array}$ & $\begin{array}{l}0.0554, \\
\quad 0.1127, \\
1.012,1919, \\
260,0.0061\end{array}$ & Plate & $\begin{array}{l}\tau^{1}=-19.7 \\
\begin{array}{l}\tau^{2}=-58.1 \\
\tau^{3}=-62.4 \\
\text { folded }\end{array}\end{array}$ \\
\hline $\begin{array}{l}(1 R, 2 S)-(-)- \\
\quad \text { Ephedrine } \\
\text { hemiedisylate }(1: 0.5)\end{array}$ & $\begin{array}{l}2 \mathrm{C}_{10} \mathrm{H}_{16} \mathrm{NO} \cdot \mathrm{C}_{2} \mathrm{H}_{4} \\
\quad 520.67\end{array}$ & $P 2_{1}, 150$ & $\begin{array}{c}a=5.71080(10) \\
b=34.0651(7) \\
c=6.6590(2) \\
\beta=90.09 \\
1295.43(5), 2\end{array}$ & $\begin{array}{l}27.47,0.032 \\
\quad 0.88\end{array}$ & $\begin{array}{l}0.0540, \\
\quad 0.1251, \\
0.984,3031 \\
357,0.0076\end{array}$ & Plate & $\begin{array}{l}\tau^{1}=23.2 \\
\tau^{2}=59.1 \\
\tau^{3}=53.6 \\
\text { folded }\end{array}$ \\
\hline $\begin{array}{l}(1 R, 2 S)-(-)- \\
\text { Ephedrine } \\
\text { esylate }(1: 1)\end{array}$ & $\begin{array}{l}\mathrm{C}_{10} \mathrm{H}_{16} \mathrm{NO} \cdot \mathrm{C}_{2} \mathrm{H}_{5} \mathrm{O}_{3} \mathrm{~S} \\
\quad 275.37\end{array}$ & $P 2_{1} 2_{1} 2_{1}, 150$ & $\begin{array}{c}a=5.4877(7), \\
b=11.9057(17), \\
c=22.639(4), \\
1479.1(4), 4\end{array}$ & $\begin{array}{l}28.16,0.000 \\
\quad 0.86\end{array}$ & $\begin{array}{l}0.1023, \\
0.2643, \\
1.078,2118, \\
169,0.0171\end{array}$ & $\begin{array}{l}\text { Needle } \\
\qquad(a \text { axis })\end{array}$ & $\begin{array}{l}\tau^{1}=23.4 \\
\tau^{2}=54.4 \\
\tau^{3}=59.5 \\
\text { folded }\end{array}$ \\
\hline $\begin{array}{l}(1 R, 2 S)-(-)- \\
\quad \text { Ephedrine } \\
\text { mesylate }(1: 1)\end{array}$ & $\begin{array}{l}\mathrm{C}_{10} \mathrm{H}_{16} \mathrm{NO} \cdot \mathrm{CH}_{3} \mathrm{O}_{3} \mathrm{~S} \\
\quad 261.34\end{array}$ & $C 2,150$ & $\begin{array}{c}a=14.287(2), \\
b=6.1075(7), \\
c=14.993(2), \\
\beta=93.211(6), \\
1306.2(3), 4\end{array}$ & $\begin{array}{l}27.47,0.029 \\
\quad 0.75\end{array}$ & $\begin{array}{l}0.0478, \\
0.1193, \\
1.101,1631 \\
179,0.0070\end{array}$ & $\begin{array}{l}\text { Needle } \\
\qquad(b \text { axis })\end{array}$ & $\begin{array}{c}\tau^{1}=-16.3, \\
\tau^{2}=-65.5, \\
\tau^{3}=-168.4, \\
\text { extended }\end{array}$ \\
\hline $\begin{array}{l}(1 R, 2 S)-(-)- \\
\quad \text { Ephedrine } \\
p \text {-tosylate }(1: 1)\end{array}$ & $\begin{array}{l}\mathrm{C}_{10} \mathrm{H}_{16} \mathrm{NO} \cdot \mathrm{C}_{7} \mathrm{H}_{7} \mathrm{O}_{3} \\
\quad 337.43\end{array}$ & $P 2_{1} 2_{1} 2_{1}, 150$ & $\begin{array}{c}a=5.7491(2), \\
b=7.1665(2) \\
c=42.0343(9) \\
1731.85(9), 4\end{array}$ & $\begin{array}{l}27.47,0.018 \\
\quad 0.87\end{array}$ & $\begin{array}{l}0.0431 \\
0.0993 \\
1.040,2353 \\
263,0.0039\end{array}$ & Plate & $\begin{array}{l}\tau^{1}=-22.8 \\
\tau^{2}=-59.3 \\
\tau^{3}=-55.4 \\
\quad \text { folded }\end{array}$ \\
\hline
\end{tabular}

were reported (Zingg et al., 1988), as well as the structures of the diastereomeric mandelates. These workers were concerned with understanding the structural basis of the chiral resolution process and the relation between solution and crystal structures, respectively, and their studies revealed two conformations of ephedrine in structures based on bilayer packings.

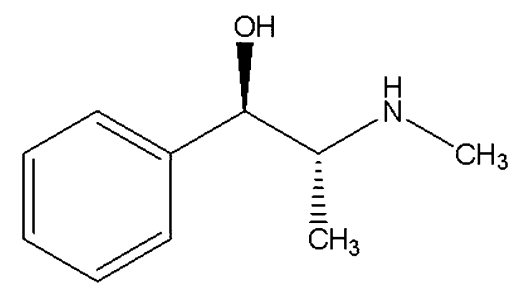

(I)

We are concerned with a more general question concerning the process of salt formation. We wanted to explore the relative roles of coulombic and steric factors in directing the packing of molecular salts and, ultimately, to see how crystallographic data might help in providing general guidance for selecting counterions for salt formation. From the previous studies (Leusen et al., 1991, 1992; Zingg et al., 1988) we expected that in our new salts ephedrine would adopt either extended or folded conformations and that, in general, the crystal packings would show polar regions where charged moieties are connected by hydrogen bonds, separated by nonpolar sections comprising phenyl rings and alkyl chains.

\section{Experimental}

Ephedrine base and the inorganic and organic acids were purchased from Sigma-Aldrich and used as supplied. All crystals were grown at room temperature from equimolar aqueous, methanolic or ethanolic solutions of the base and chosen acid. A glass, $10 \mathrm{ml}$ jacketed vessel connected to a circulating water bath was used in these experiments. This allowed components to be dissolved at $323 \mathrm{~K}$ in some experiments so that crystallization could be induced by cooling, while in others the vessel was left open so that evaporative crystallization could occur. In a separate series of experiments solutions of the pure base in water were crystallized to yield a hemihydrate which was dehydrated to an anhydrous form in a desiccator. Single-crystal X-ray diffraction data was collected using a Nonius Kappa CCD diffractometer running routinely at $150 \mathrm{~K}$. Graphite-monochromated Mo $K \alpha$ radiation $(\lambda=0.71073 \AA)$ was used. Structure solution was performed either with SIR92 (Altomare et al., 1994) or SHELXS97 (Sheldrick, 1997a), with subsequent refinement achieved using SHELXL97 (Sheldrick, 1997b). The nomenclature used to describe the salt forms of the sulfonic acids is that used widely in the pharmaceutical industry, with besylate 


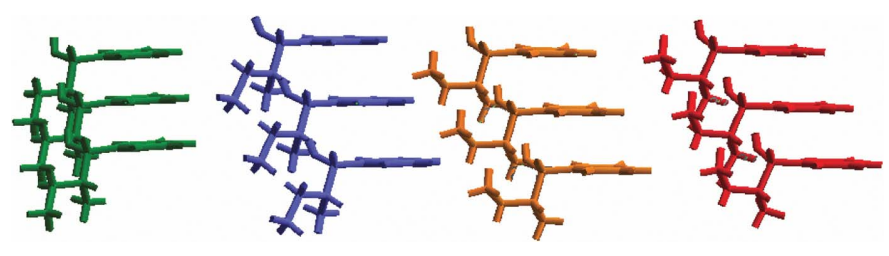

Figure 1

$\pi-\pi$ stackings of ephedrine from various salt structures. The figures in brackets give the inter-stacking distances in $\AA$. Key: green = ephedrine glycolate ('extended') $(3.00,3.14)$; blue $=$ ephedrine hydrochloride ('extended') $(3.23,3.10)$; orange $=$ ephedrine bisulfate ('folded') $(3.14$, $3.02)$; red = ephedrine nitrate ('folded') $(2.95,2.92)$.

representing the counterion benzenesulfonic acid, edisylate (ethanedisulfonic), esylate (ethanesulfonic), mesylate (methanesulfonic) and tosylate (toluenesulfonic), respectively.

\section{Results}

Table 1 lists the 17 salt systems, together with ephedrine hemihydrate and anhydrous forms, along with summaries of the crystallographic data. ${ }^{1}$ We note that for some structures (e.g adipate, hemihydrate, malonate) the ellipsoid plots indicate the presence of unresolved disorder. In the discussion below we describe the details of some of the specific structures, while here we make some general observations.

Overall it is clear that the molecular packing in many of these solids reflects the amphiphilic nature of the molecular structure of ephedrine itself, with the almost ubiquitous existence of a molecular bilayer, in which the polar hydroxyl and (protonated) amino functionalities are sandwiched between the nonpolar aromatic moieties. This is as expected from the previously solved salt structures (Leusen et al., 1991, 1992; Zingg et al., 1988) and is indeed seen in other systems which have similar amphiphilic molecular features such as remacemide (Lewis et al., 2005). In the case of the anhydrous solid, the polar functionalities are hydrogen-bonded directly through $-\mathrm{OH} \cdots \mathrm{N}-$ interactions, while in the hemihydrate these interactions are modified by the inclusion of further extensive hydrogen bonding involving the water molecules. In the salts the bilayer expands to incorporate the counterion (and occasionally additional water molecules) through combined coulombic and hydrogen-bonded interactions. In each salt there are two distinct $-\mathrm{N}-\mathrm{H} \cdots$ acceptor distances, one short and one slightly longer. The short distances lie in the range 1.8 (malonate) to $2.2 \AA$ (hydrochloride), while the long distances are in the range 1.9 (dihydrogenphosphate) to $3.0 \AA$ (tartrate trihydrate). In many cases the stability of the bilayer is enhanced through aromatic $\pi-\pi$ stacking with distances from the $\mathrm{H}$ atom to the closest ring carbon in the range 4.5 (acetate) to $2.8 \AA$ (maleate; Desiraju \& Steiner, 1999). Typical $\pi-\pi$ stacks taken from four salts are shown in Fig. 1, indicating stacking distances between 3.19 and $2.95 \AA$. The layers are

\footnotetext{
${ }^{1}$ Supplementary data for this paper, including a complete CIF and ellipsoid plots for all structures determined, are available from the IUCr electronic archives (Reference: BK5025). Services for accessing these data are described at the back of the journal.
}

usually interlinked by face-to-edge or methyl-to-face close contacts with $d_{\mathrm{H}-\pi \text { centroid }}$ distances between 3.6 (esylate) and $2.8 \AA$ (dihydrogenphosphate). In the case of the adipate, esylate, besylate and tosylate anions, the existence of additional non-polar interactions between the ions destroys the ephedrine bilayer to yield structures with mixed and alternating layers. In the besylate and tosylate this occurs owing to the possibility of additional anion-anion and cation-cation $\pi$ $\pi$ and face-to-edge interactions; in the adipate, its extended non-polar alkyl chain requires that the bilayer is destroyed and in the case of esylate, the ethyl moiety fits between the phenyl rings of the ephedrine.

The protonated ephedrine molecule adopts one of two conformations in these structures: 'folded' or 'extended' owing to the three torsions encompassing the chiral $\mathrm{C}$ atoms $\mathrm{C} 7$ and C8. Only the 'folded' conformation includes an intramolecular hydrogen bond. These conformers are shown in Fig. 2(a), and Table 1 incorporates the measured values (achieved using CERIUS ${ }^{2}$ (Accelrys Inc., 2003) of the dihedral angles, $\tau^{1}, \tau^{2}$ and $\tau^{3}$, for ephedrine molecules within each crystal structure. Little variation with respect to the dihedral angles involved in either the 'extended' or 'folded' conformation can be seen. To demonstrate this, individual units of 'extended' and 'folded' ephedrine were isolated and overlaid from several salt forms, as seen in Fig. 2(b). This conveys both the similarity in the molecular conformation for units of each conformation and the variation between the two types arising from the torsional

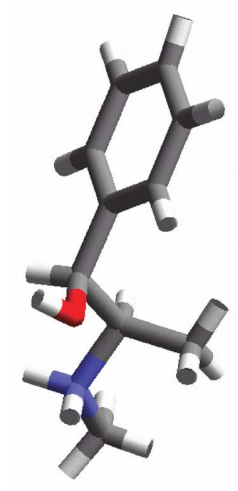

'Extended'

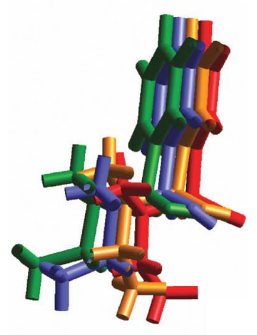

Figure 2

$$
\begin{aligned}
& \text { Dihedral angles } \\
& \begin{array}{l}
\tau^{1}=C^{5}-C^{6}-C^{7}-O^{1} \\
\tau^{2}=O^{1}-C^{7}-C^{8}-N^{1} \\
\tau^{3}=C^{7}-C^{8}-N^{1}-C^{10}
\end{array}
\end{aligned}
$$

(a)

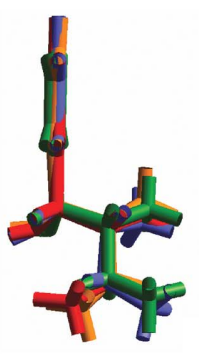

(b)

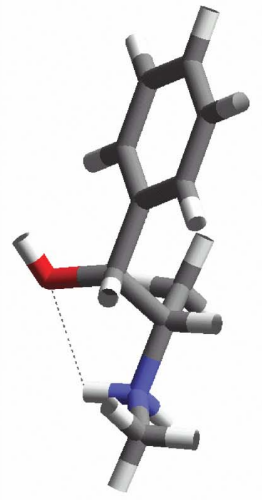

'Folded'

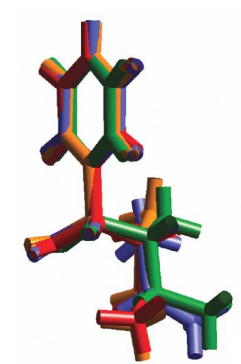

(a) The two conformers of ephedrine. (b) Comparison of ephedrine conformations from selected salt structures. Key: green $=$ ephedrine glycolate ('extended'); blue = ephedrine hydrochloride ('extended'); orange $=$ ephedrine bisulfate ('folded'); red $=$ ephedrine nitrate ('folded'). 
flexibility and the intramolecular hydrogen bond. The main difference between the units arises from the variation in $\tau^{3}$ (approximately $100^{\circ}$ ) from one conformation to the other. Ten structures exhibit the extended form and nine the folded form. In the 12 ephedrine structures examined by Leusen et al. (1991) they noted that nine exhibited the extended conformer but showed that this could not be rationalized by the difference in internal energy since this was insignificant. We have used a MOPAC conformational search to confirm this result and to show that both conformers represent minima in the overall $\tau^{2}, \tau^{3}$ landscape. Our new structures do not appear to support their notion that the extended conformation is associated with face-to-edge aromatic interactions.

Overall the crystals studied had either needle or plate morphologies. For those that were needles (pure base, acetate, maleate monohydrate, malonate, glycolate, hydrochloride, dihydrogen phosphate, bisulfate, esylate, mesylate), the needle direction always coincided, as expected, with the direction of the strong coulombic interactions and shortest crystallographic axis. These data are included in Table 1. Although we did not perform a dedicated polymorph search, none were found.

\section{Ephedrine neutral base and hemihydrate}

Fig. 3 (visualized in MERCURY1.4; Bruno et al., 2002) shows how in the anhydrous neutral base structure, ephedrine molecules are linked along $\mathbf{a}$ in hydrogen-bonded chains through alternate $-\mathrm{N} \cdots \mathrm{H}-\mathrm{O}-$ interactions between hydroxyl and amino groups, and along b by $-\mathrm{C}-\mathrm{H} \cdots$ ring interactions between methyl groups and phenyl rings on adjacent molecules. The bilayers are then linked along the $c$ axis by $\mathrm{T}$-shaped aromatic $-\mathrm{C}-\mathrm{H} \cdots \pi$ interactions. The hemihydrate is also based on a bilayer structure, but in this case the inclusion of water molecules into the polar core of the

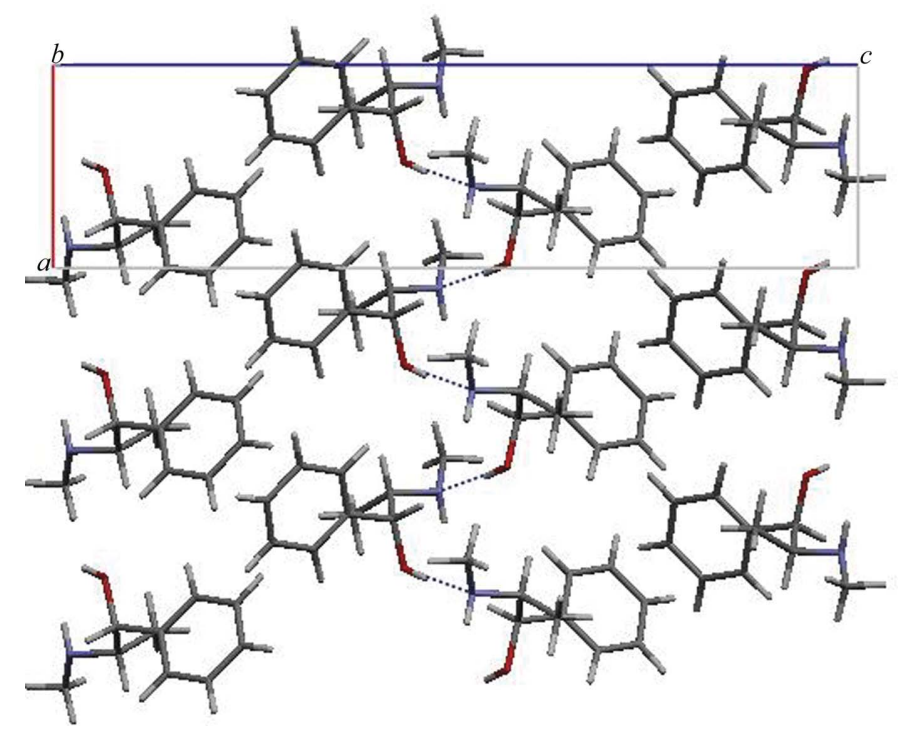

Figure 3

Projection of ephedrine free base viewed down $\mathbf{b}$. layer enables a different hydrogen-bonding pattern. Our single-crystal structure appears to be essentially similar to that of Krebs et al. (2001) solved from powder data. The bilayers are created by utilizing hydrogen-bonded dimers linked via hydroxyl-water contacts along a and $-\mathrm{C}-\mathrm{H} \cdots \pi$ interactions along $b$. These layers are then further linked along $c$ by faceto-edge contacts between neighbouring phenyl rings. In both of these structures the molecule adopts an extended conformation.

\section{Inorganic acids}

Fig. 4 shows the hydrochloride salt which is essentially the same as in previous structure solutions (Bergin, 1971). This bilayer structure is held along by coulombic $-\mathrm{N}-\mathrm{H}_{2}{ }^{+} \ldots \mathrm{Cl}^{-}$ interactions and along a by chloride-methyl contacts. The bilayers are then stacked along $\mathbf{c}$ by face-to-edge contacts between the interdigitated aromatic rings. The dihydrogenphosphate and bisulfate structures (not shown) follow the same pattern, but here the stereochemistry of the anions allows the bilayer to be held by coulombic interactions, hydrogen bonds and $\pi-\pi$ stacking. These layers are then interlinked by aromatic face-to-edge contacts. The planarity of the nitrate ion leads to bilayers in which the expected coulombic interaction and hydrogen bonds between the hydroxyl group and nitrate oxygen are supplemented by weaker $-\mathrm{C}-\mathrm{H} \cdots \mathrm{O}-\mathrm{N}-$ interactions, as seen in Fig. 5. The bilayer is further stabilized by $\pi-\pi$ stacking between the aromatic rings and the bilayers are again held together by face-to-edge contacts.

\section{Carboxylic acids}

Structures of the acetate, adipate, maleate, malonate, glycolate, malate and tartrate were solved. In all of these there is, of course, a primary coulombic interaction between the acid anion and the ephedrine cation. Beyond this the actual

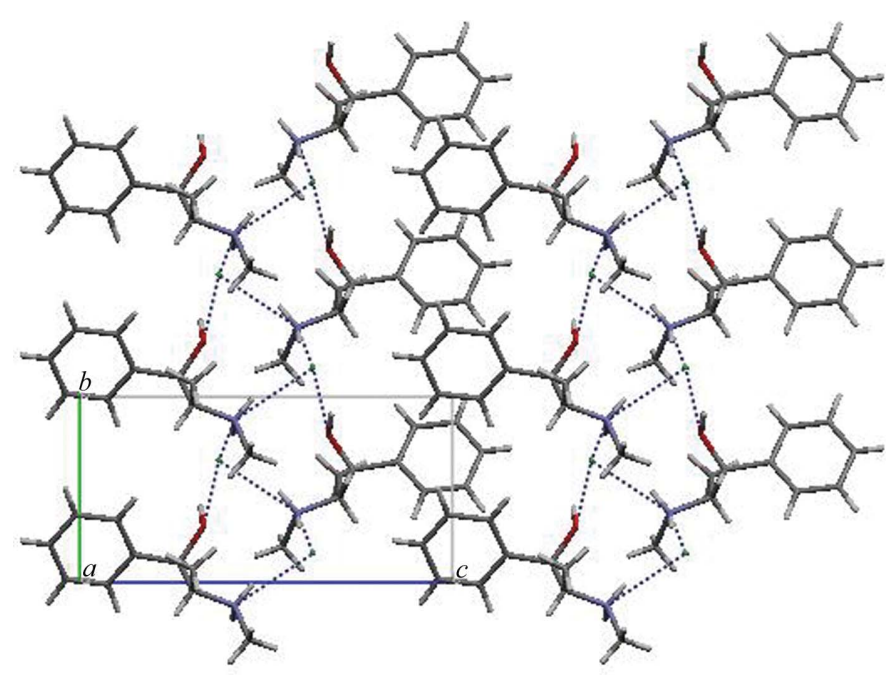

Figure 4

Projection of the hydrochloride salt viewed down $\mathbf{a}$. 
packing is determined by the nature of the acid involved. The acetate is the simplest comprising (100) bilayers hydrogen bonded as seen in Fig. 6. These layers are interdigitated and held by methyl-to-face and aromatic face-to-edge interactions. In the malonate the dual functionality of the diacid enables the interlinking of bilayers by additional hydrogen bonding along the $a$ axis. In the maleate the increased non-polar nature of the acid, together with the incorporation of water, destroys the bilayer structure totally and creates a three-dimensional hydrogen-bonded network. The acid itself contains an intramolecular hydrogen bond, effectively removing one of its potential hydrogen-bonded functionalities; this is compensated for by the inclusion of water.

This trend continues in adipate, which again no longer displays the bilayer features. Here the extended non-polar [$\left(\mathrm{CH}_{2}\right)_{4}-$ ] chain interacts with alternate phenyl rings and the bilayer structure is lost, as seen in Fig. 7. Hydrogen-bonded chains of acid anions run along $\mathbf{b}$. To these chains are bound to ephedrine cations through $-\mathrm{C}-\mathrm{H} \cdots$ aromatic and $-\mathrm{O}-$ $\mathrm{H} \cdots \mathrm{O}-$ and $-\mathrm{N}-\mathrm{H}^{+} \cdots \mathrm{O}-$ interactions. The case of the glycolate represents a further complication, being a hydroxy acid. Fig. 8 illustrates some features of the structure. Here, the dual functionality of the acid allows the creation of sheets, much in the same ways as the inorganic ions. One hydrogenbonded chain runs along the $c$ axis connecting molecules via

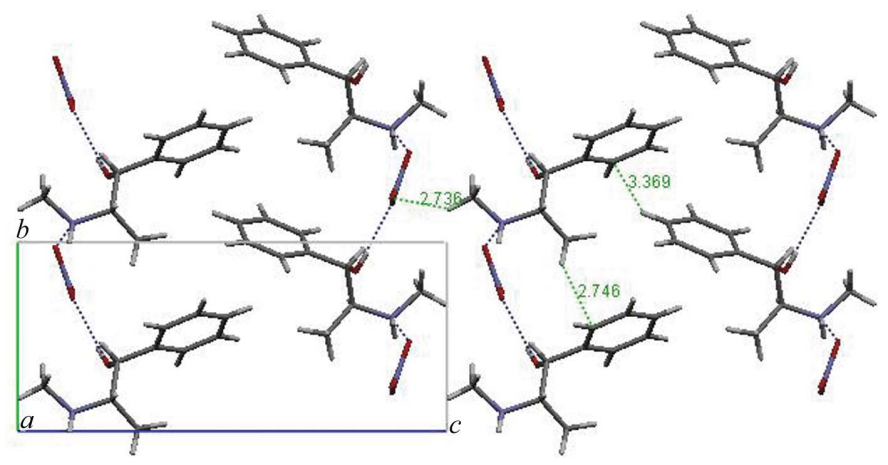

Figure 5

Projection of the nitrate salt viewed down a.

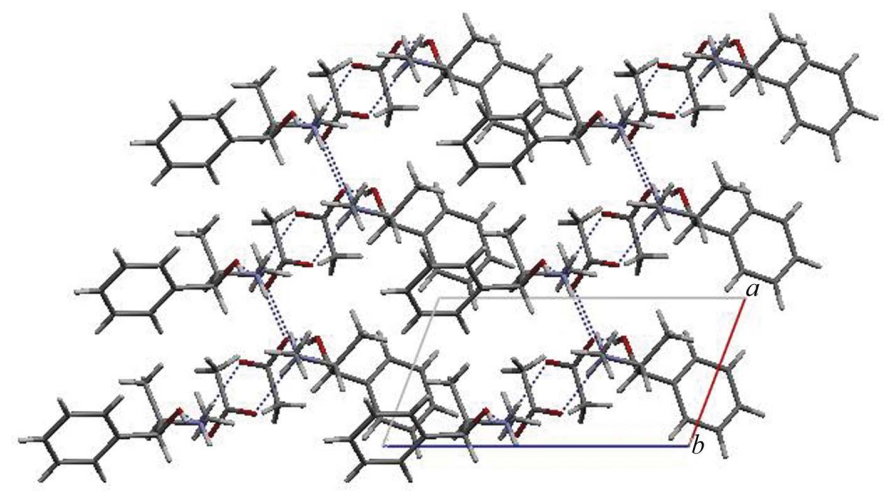

Figure 6

Projection of the acetate salt viewed down $\mathbf{b}$. carboxylate-amino and hydroxyl-carboxylate interactions. A second identical chain runs along the $b$ axis, creating hydrogen-bonded (100) sheets. These sheets are stacked along the $a$ axis and held by face-to-edge methyl-phenyl and phenyl-phenyl close contacts. The malate structure is a very similar bilayer structure with the hydrogen bonding creating a (001) sheet. These sheets are held by face-to-edge contacts. The hydrated tartrate salts are similar; the structures (not shown) retain a bilayer form with hydrogen-bonded interactions in the core of the bilayer and the bilayers linked by further hydrogen bonding into sheets. Aromatic face-to-edge ring interactions link the sheets along the $c$ axis. In the case of the monohydrate this involves interdigitation of the phenyl rings, while in the trihydrate the bilayer is translated along the $c$ axis.

\section{Sulfonic acids}

The mesylate follows a now familiar pattern in which coulombic and hydrogen-bonded interactions from sulfonate $\mathrm{O}$ atoms to amino and hydroxyl groups create an (001) layer, with layers interdigitated and held by aromatic face-to-edge contacts. The addition of one methylene group in the esylate changes the nature of the bilayer, which now exposes (Fig. 9) both phenyl rings of the ephedrine and the methyl group of the sulfonic acid. The bilayers have close methyl-aromatic and face-to-edge aromatic contacts. In the case of the disulfonate edysilate, each anion now bridges two ephedrine cations via hydrogen bonds and coulombic interactions which, together with methyl-aromatic close contacts create (010) sheets interdigitated with face-to-edge interactions. The aromatic nature of the besylate totally destroys the ephedrine bilayer and creates (Fig. 10) a mixed sheet of cations and anions held

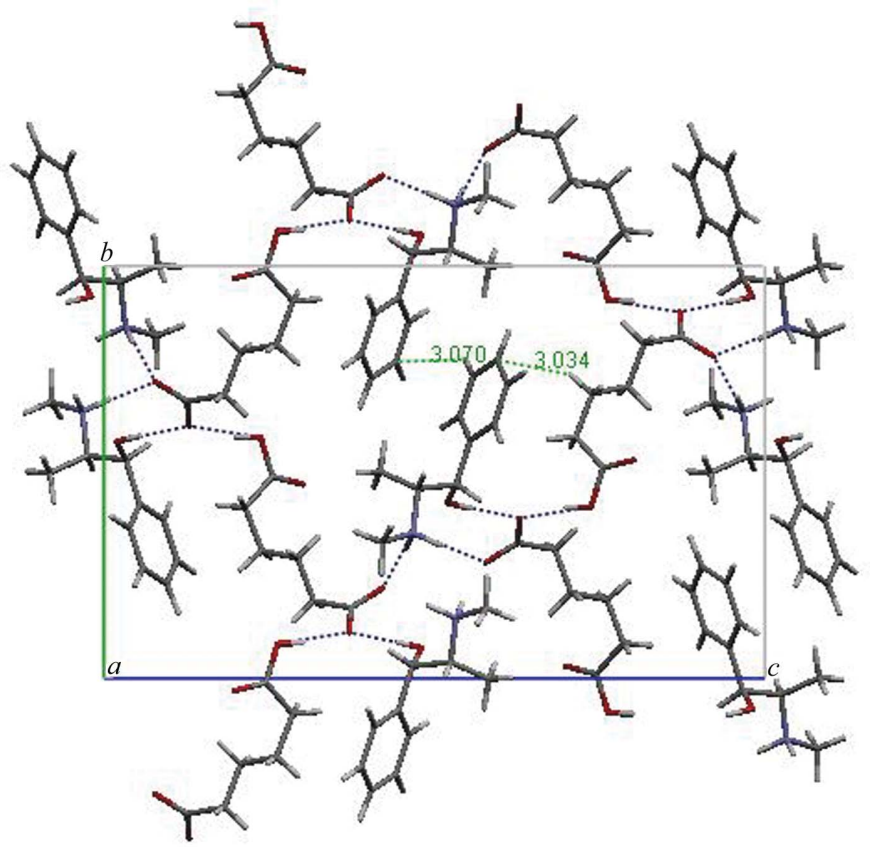

Figure 7

Projection of the adipate salt viewed down $\mathbf{a}$. 
via coulombic oxygen-amino interactions and oxygen hydroxyl hydrogen bonds. These layers are further stabilized by $\pi-\pi$ stacking and methyl-to-face interactions and are held with face-to-edge contacts between phenyl rings of adjacent sulfonic acid anions and ephedrine cations. Finally in the tosylate, the bilayers again comprise both anions and cations. Layers are held together by the usual combination of coulombic, hydrogen bonding and methyl-to-face contacts. Interlayer interactions are face-to-edge on both sides.

\section{Conclusions}

This study has provided the structures of 17 salts of the base ephedrine, enabling for the first time the opportunity to compare and contrast the impact of various factors on the crystal packing of a single molecular entity. It is clear that the packings observed incorporate, as expected, both bilayer structures of the ions and the two conformations of the ephedrine ion. It is also evident that the crystal structures of ephedrine base and hydrate contain all the essential structural elements which are then transferred over into the salts, with ions fitting within ephedrine bilayers. The bilayers are typically interconnected through aromatic face-to-edge contacts. With increasing size and hydrophobicity of the anion these layers either incorporate the counterion (besylate and tosylate) or can be destroyed altogether (adipate). In the case of the inorganic salts it is clear that crystal packings are determined by the organic moeties rather than the inorganic ions, even though their additional contribution to the lattice energy is presumably quite large.

The factors determining the ephedrine conformation are not clear. NMR studies of both neutral (Portoghese, 1967) and

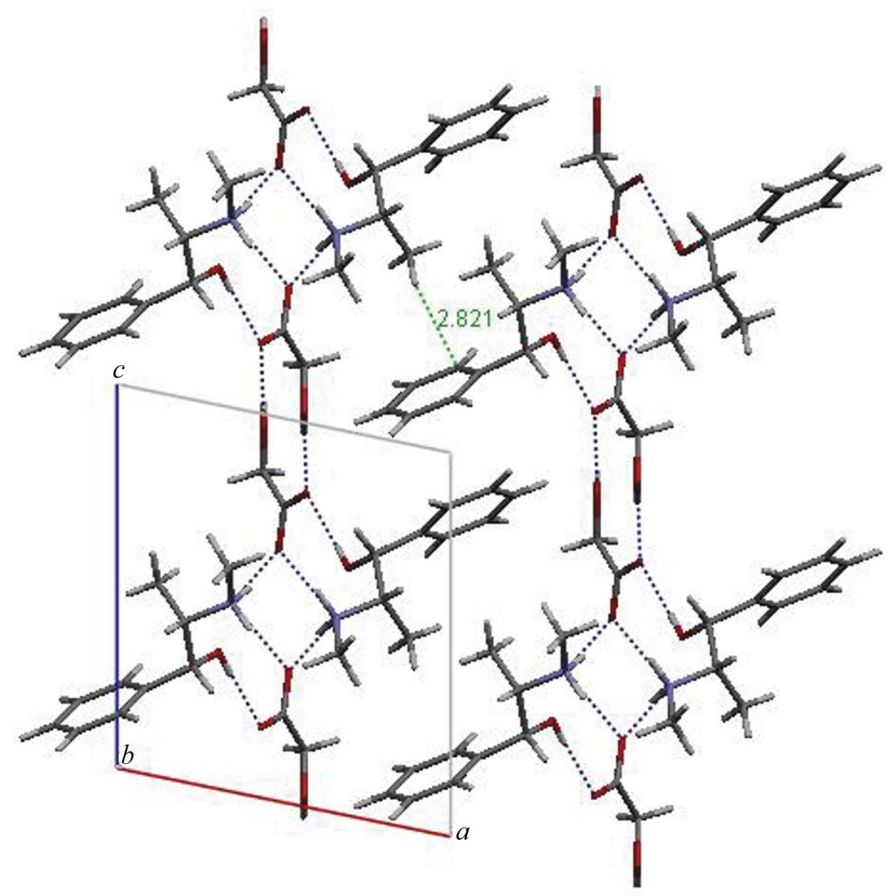

Figure 8

Projection of the glycolate salt viewed down $\mathbf{b}$. protonated (Zingg et al., 1988) ephedrine in organic solvents have shown the folded conformer with the intramolecular hydrogen bond to be the favoured form. This suggests that in those instances in which the extended conformer exists, it must be imposed by packing and hydrogen-bonding constraints in the crystalline state. Given the previous calculations (Leusen et al., 1991) showing that the energy barrier between conformers is less than $4.19 \mathrm{~kJ} \mathrm{~mol}^{-1}$, such a change in conformation could clearly occur during nucleation and crystal growth.

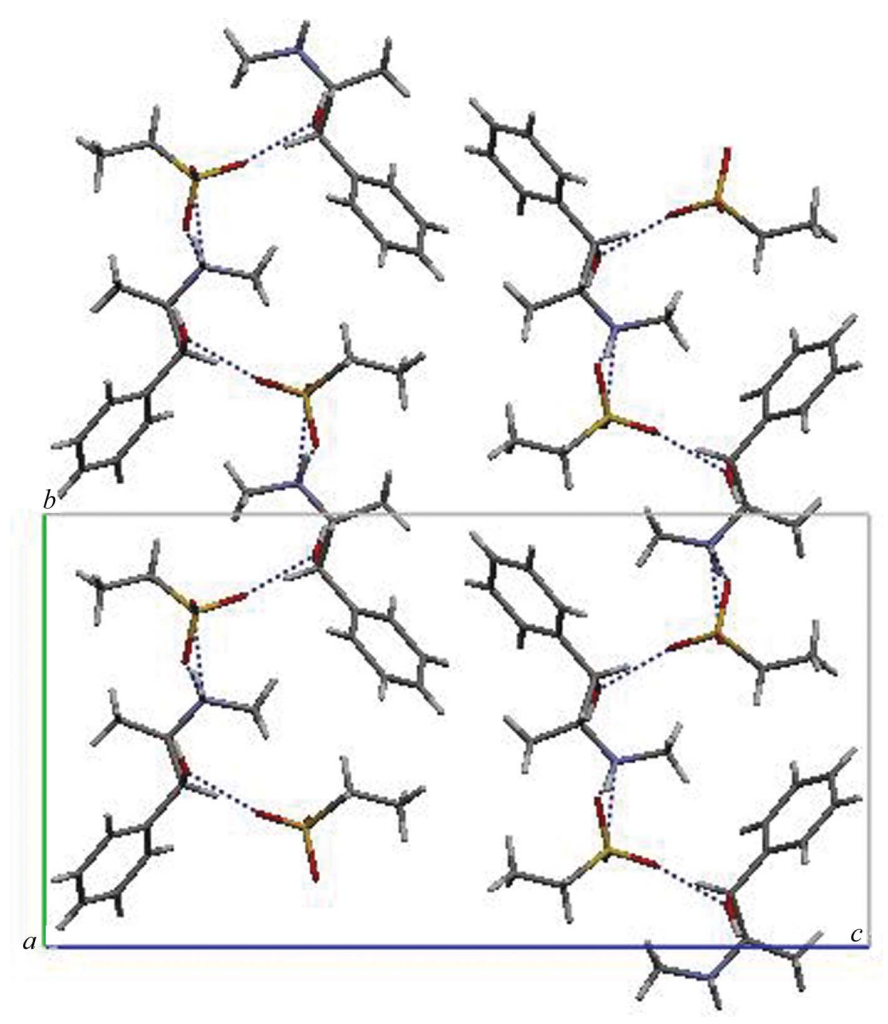

Figure 9

Projection of the esylate salt viewed down $\mathbf{a}$.

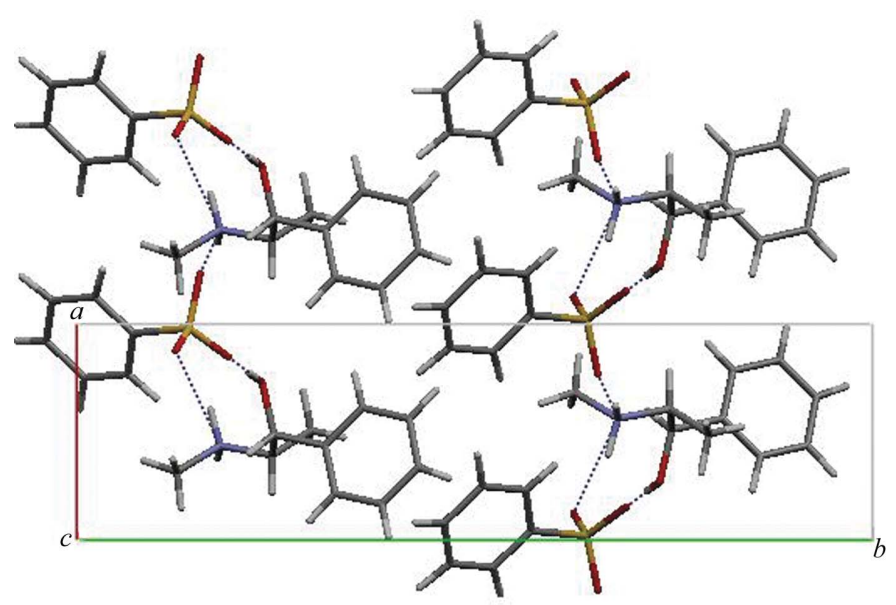

Figure 10

Projection of the besylate salt viewed down c. 
The authors would like to thank both Robin G. Pritchard and Amy L. Gillon for their contribution to the crystallographic analysis performed within this work. In addition, Edwin A. Collier would like to thank AstraZeneca for the provision of funding to support this study.

\section{References}

Accelrys Inc. (2003). Cerius ${ }^{2}$. Accelrys, San Diego, California USA. Allen, F. H. (2002). Acta Cryst. B58, 380-388.

Altomare, A., Cascarano, G., Giacovazzo, C., Guagliardi, A., Burla, M. C., Polidori, G. \& Camalli, M. (1994). J. Appl. Cryst. 27, 435436.

Bergin, R. (1971). Acta Cryst. B27, 381-386.

Bruno, I. J., Cole, J. C., Edgington, P. R., Kessler, M., Macrae, C. F., McCabe, P., Pearson, J. \& Taylor, R. (2002). Acta Cryst. B58, 389397.

Collier, E. A. (2004). PhD Thesis, University of Manchester, England. Desiraju, G. R. \& Steiner, T. (1999). The Weak Hydrogen Bond in Structural Chemistry and Biology. Oxford University Press.

Gould, P. L. (1986). Int. J. Pharmaceut. 33, 201-207.

Hearn, R. A. \& Bugg, C. E. (1972). Acta Cryst. B28, 36623667.

Hearn, R. A., Freeman, G. R. \& Bugg, C. E. (1973). J. Am. Chem. Soc. 95, 7150-7154.
Jones, H., Cox, B. \& Davey, R. J. (2005). J. Phys. Chem. B, 109, $5273-$ 5278.

Krebs, F. C., Jorgensen, M., Lebech, B. \& Frydenvang, K. (2001). J. Appl. Cryst. 34, 203-207.

Leusen, F. J. J., Bruins Slot, H. J., Noordik, J. H., van der Haest, A. D., Wynberg, H. \& Bruggink, A. (1991). Recl. Trav. Chim. Pays-Bas, 110, 013-018.

Leusen, F. J. J., Bruins Slot, H. J., Noordik, J. H., van der Haest, A. D., Wynberg, H. \& Bruggink, A. (1992). Recl. Trav. Chim. Pays-Bas, 111, 111-118.

Lewis, G. R., Steele, G., McBride, L., Florence, A. J., Kennedy, A. R., Shankland, N., David, W. I. F., Shankland, K. \& Teat, S. J. (2005). Cryst. Growth Des. 5, 427-438.

Malone, J. F. \& Parvez, M. (1978). Acta Cryst. A34, S76.

Portoghese, P. S. (1967). J. Med. Chem. 10, 1057-1063.

Shanker, R. (1994). Pharmaceut. Res. 11, S-236.

Sheldrick, G. M. (1997a). SHELXS97. University of Göttingen, Germany.

Sheldrick, G. M. (1997b). SHELXL97. University of Göttingen, Germany.

Stahl, P. H. \& Wermuth, C. G. (2002). Editors. Handbook of Pharmaceutical Salts: Properties, Selection and Use. Chichester, England: Wiley-VCH.

Tong, W. \& Whitesell, G. (1998). Pharmaceut. Dev. Technol. 5, 579582.

Zingg, S. P., Arnett, E. M., McPhail, A. T., Bother-By, A. A. \& Glikerson, W. R. (1988). J. Am. Chem. Soc. 110, 1565-1580. 